\title{
Evaluation of Rubber/Mild Steel Bonds Failure after Exposure in Marine Environment
}

\author{
Ismaliza Ismail and M. K. Harun
}

\begin{abstract}
The use of rubber/metal bonded composite is growing in the offshore industries as well as in the automotive components. Maintaining a good adhesion between rubber to substrate bond is a crucial importance in ensuring a satisfactory product performance in service. Bond failure attributes to the severe product performance failure. Exposure under salt environment can cause the bond failure due to corrosion reaction. Therefore the durability of rubber/metal bond in seawater, using natural rubber bonded to mild steel by proprietary bonding agent is studied. The locus of failures was determined at primer/metal oxide layer and the results are presented in the SEM and EDS analysis on both of the interfacial failures area. The adhesion failure mechanism is proposed where the bond delamination was found precedes the under film corrosion.
\end{abstract}

Index Terms-Bond, corrosion, marine, mild steel, rubber.

\section{INTRODUCTION}

Most rubber engineering components are macro-composites, incorporating not only rubber but also pieces of rigid material such as metal, to which the rubber is bonded. Bonded rubber components experience highly variable service conditions involving many combinations of environments and stresses which could cause the bond failure. Chemical environments could attack the bond line and interact differently for different materials which lead to a variety of failure mechanisms. In the past, such bond failure has been noted to be due the attacks by species such as ozone or solvents at the bond [1] or rupturing within the adhesive and the metal surface induced by corrosion. Rubber bonds to metal substrates interface are prone to attack by environmental agents that can lead to the corrosion of the metal itself. In temperate countries, the undersides of road vehicles for example are exposed to highly corrosive conditions, because of the use of salt to suppress ice formation on roads in the winter and it was found that bonded rubber to metal component in vehicle suffers bond failure when exposed to this aggressive media [2], [3].

The failure mechanisms of bonded rubber to metal in marine environment have not been widely studied yet. There has been some works on corrosive attack in seawater at

Manuscript received March 7, 2013; revised May 22, 2013.

Ismaliza Ismail is with the Faculty of Applied Science, Universiti Teknologi MARA, 40450 Shah Alam, Selangor, Malaysia, on study leave from the Rubber Research Institute of Malaysia, Malaysian Rubber Board, P.O. Box 10150, 50908 Kuala Lumpur, Malaysia (email: ismaliza@lgm.gov.my).

Mohamad Kamal Harun is with the Faculty of Applied Science, Universiti Teknologi MARA, 40450 Shah Alam, Selangor, Malaysia (e-mail mkharun@gmail.com). rubber-to-metal bond been studied by [2], [4]-[6]. However no conclusive determination of the mechanisms of the failure. Further conflict also arises with [4] and [5] finding who reported that the rubber to steel bond is stable in seawater which contradicts with [2] who found that the bond failed in the similar condition. The conflicting observations found from the previous workers leave the bond failure mechanism of automotive component in a mystery which begs for further investigation. The question that always arises is what has cause the rubber-to-metal bond failure. Is that due to the corrosion or just being attacked by salt water? Arguments on whether corrosion causes coating de-adhesion or whether de-adhesion precedes corrosion have always arisen. Therefore there is a need to determine what causes the bond failures and it is worth to investigate the bond failure mechanism between the rubber and metal substrate. Improved knowledge on the failure mechanism in specific conditions will be useful in order to access the bond durability of the component. Thus in this study, the effects of salt corrosion on the adhesion failure of rubber to carbon steel is discussed.

\section{EXPERIMENTAL}

\section{A. Materials}

The bonding agents employed in this work is the Chemlok 205 and Chemlok 220 manufactured by Lord Corporation, Hong Kong. Both of the bonding agents are proprietary however reference to the scientific literatures [4], [7] suggests that the 205 primer comprises of chlorinated rubber based and phenolic resin in a solvent containing metal oxides (zinc and titanium). The 220 topcoat may contain chlorinated rubbers carbon black and a cross linking agent (sulphur and possibly a dinitroso-containing moiety).

\begin{tabular}{ll}
\multicolumn{2}{c}{ TABLE I: RUBBER COMPOUND FORMULATION } \\
\hline \hline Ingredients & $\mathrm{Phr}$ \\
\hline SMR CV60 & 100.0 \\
Zinc Oxide & 5.0 \\
Stearic acid & 2.0 \\
N330 black & 25.0 \\
Process oil & 2.5 \\
Antioxidant/antiozonant, HPPD & 3.0 \\
Antiozonant wax & 2.0 \\
CBS & 1.5 \\
Sulphur & 1.5 \\
\hline \hline
\end{tabular}

Natural rubber (NR) compound was prepared according to the formulation as shown in Table I. SMR CV60 (supplied by 
Malaysian Rubber Board) was used in this work. The mixing and compounding of the rubber ingredients was done on a two-roll mill mixer. The cure characteristic of the rubber compound was determined by a Monsanto Rheometer at $140^{\circ} \mathrm{C}$. The substrate was a mild steel strip $60 \times 25 \times 3 \mathrm{~mm}$ consisted of carbon 0.0835 , silicon 0.0085 , manganese 0.083 , ferum 0.5171 and oxygen 0.3826 on the surface.

\section{B. Bonding of Rubber to Metal}

Peel test samples were prepared according to BS 903 A21 [8]. Prior to the bonding, the steel surface was polished by an Automatic Surface Grinding Machine to 800 grit size, rinsed twice with both deionized water and acetone, and dried with tissue paper. The 205 primer was applied uniformly with a small plastic applicator onto the cleaned metal surface and the solvent in the primer was allowed to evaporate to give the dry thickness of $15 \pm 5 \mu \mathrm{m}$. Then the 220 topcoat was applied on the top surface of the primer coat and allowed to dry to give total adhesive thickness of $43 \pm 7 \mu \mathrm{m}$. The rubber strip was placed over the adhesive-coated metal in a $6 \mathrm{~mm}$ cavity mould and the assembly was subjected to compression molding curing in a hydraulic press at $140^{\circ} \mathrm{C}$ and 100 Psi for 20 minutes. Some samples were prepared by applying the 205 primer layer or both the $205 / 220$ topcoat on the metal surface and cured without rubber at $140^{\circ} \mathrm{C}$ for 20 minutes. Some samples omitting the 205 primer and the rubber was cured on the 220 topcoat coated on the steel surface. Prior to the salt spray exposure, the rubber tail of the peel test samples were tied back with a nylon string so that the unbonded region was exposed during exposure. However care has been taken out to ensure that the stress was not developed at the bond. All the samples were sealed at the back using commercial epoxy adhesive leaving four edges exposed to the test environment. The dry thickness of the coated samples prior to curing was measured using a Phynix digital coating thickness gauge.

\section{Salt Spray Test}

Salt spray test according to ASTM B117 [9] was run on each sample. The test samples were placed on the rack in the salt spray cabinet and allowed to expose over 1000 hours at $35^{\circ} \mathrm{C}$. The test solution consisted of $5 \%$ by weight of analytical grade of $\mathrm{NaCl}$ in deionized water. The samples had being withdrawn periodically to inspect the corrosion behavior and bond delaminating.

\section{Analytical Procedures}

Surface analysis- Scanning Electron Microscopy (SEM) with Energy Dispersive X-rays Spectrometry (EDS) was employed to trace the species on the failure interfaces. The test portion of the sample was cut and placed onto the specimen stub with carbon double-sided tape. The specimen was then prepared for examination by evaporative coating with ultra-thin layer of platinum under high vacuum. This provides a conducting layer that permits SEM examinations. JOEL FESEM JSM $6701 \mathrm{~F}$ was operated at $15 \mathrm{kV}$ with $15 \mathrm{~mm}$ working distance. For elemental analysis, Energy dispersive $\mathrm{x}$-ray (EDS) was used. The analysis is based on semi quantitative measurement of element extracted from a specific window size. EDS was performed at 1000x magnification. The qualitative elements present in weight $\%$ for samples stain surface and control surface is measured. Spectra for samples after exposure was measured on both failed surfaces. Reference spectra were obtained on the bare mild steel and on the 205 primer and 220 topcoats that were cast onto the steel substrates and cured at the elevated temperature.

\section{E. Bonding Test}

All peel test specimens were bond tested on an Instron Model 4502 test instrument. A 90 degree mode test according to BS903 A21 [8] was used. The peel strengths were measured at selected exposure time.

\section{RESUlTS AND DISCUSSIONS}

\section{A. Evaluation of Rubber to Metal Bond Failures}

Exposed mild steel shows formation of red rust after twenty-four hours exposure in salt spray chamber. After forty-eight hours the rubber/220 on mild steel is completely detached. Reference [10] was referred for accessing the adhesion of the 205 primer film and the 220/205 film on the steel substrate by applying and removing a pressure-sensitive adhesive tape. The bond was detached immediately after removing the sample from the test chamber. It was found that the bond failure starts at the exposed edges towards the middle of the sample after seventy-two hours of exposure. It was also discovered that the 205 primer sample detached not only at the edges but also randomly at the middle. Similar behaviour was observed on the rubber/220/205 sample after exposure in the salt spray cabinet. The bond failure started at the edges and penetrated further towards the centre with exposure time as illustrated in Fig. 6. Towards the middle, the rubber still intact on the steel suggested that the bond at this area is good. The exposed steel was heavily corroded and the shiny surface discovered on the failed area and start to corrode after one hour replacing back in the test chamber.

\section{B. Locus of Failure}

In order to confirm the loci of failures, SEM and EDS measurement were performed on both sides of the metal and rubber surfaces as demonstrated in Fig. 1 and Fig. 2 respectively. To make sure that the EDS analysis was measured at the surface, the angle of incidence of the IR beam was $60^{\circ}$ from the surface. The steel is shiny after rubber/220/205 sample failed. SEM images discovered mark of grit line on the failed rubber surfaces suggested that the failure is at the primer/metal interface. The results were confirmed by EDS spectra on both sides of the failed area. Similar locus of failures are discovered for coated steel with the 205 primer and the 220/205samples. It was found that omitting 205 primer bonded rubber to metal failed at 220/metal interface. EDS analysis on each sample type reveals that both failed surfaces have different spectra. This is emphasised by comparing the EDS spectra which each side shows similar spectra to the reference samples Fig. 3. Significance differences between the spectra on both failed surfaces are consistent with the visual observation and the presence of iron on polymer sides proved that the failure is at the primer/metal oxide layer. The results obtained here 
implies that the bond between rubber/220 and 220/primer are good although after exposure in the salt environment.
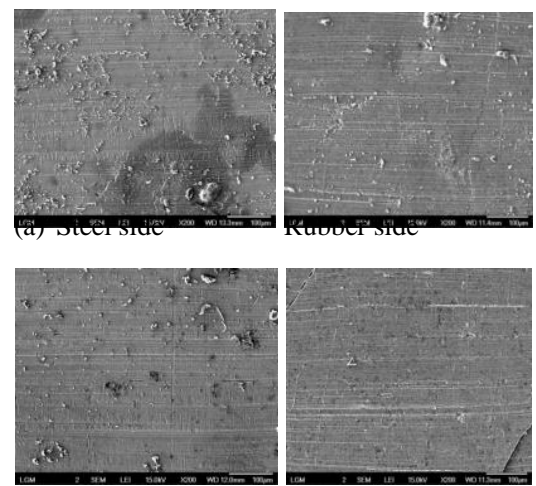

(b) Steel side Rubber side
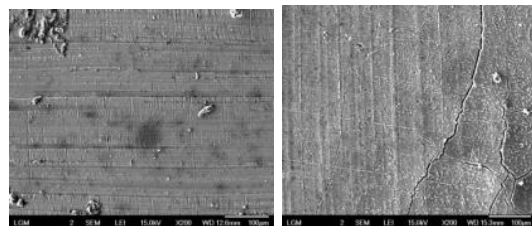

(c) Steel side

Rubber side

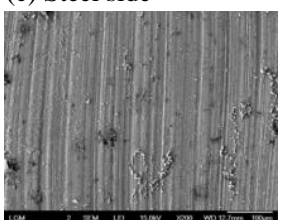

(d) Steel side

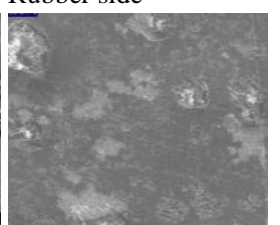

Rubber side

Fig. 1. SEM micrographs on failed surfaces after exposure in salt spray chamber at 35oC, magnification: 200x. (a) rubber/220 sample (b) rubber/220/205 sample (c) 205 primer sample (d) 220/205 sample
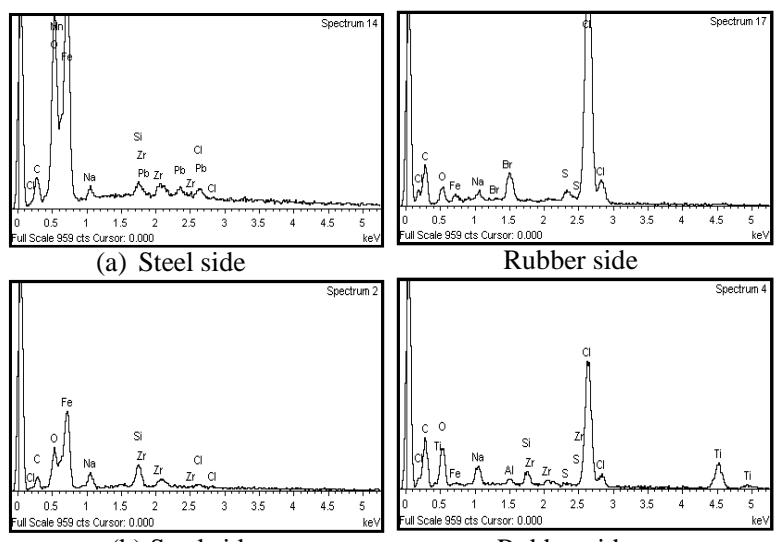

(b) Steel side
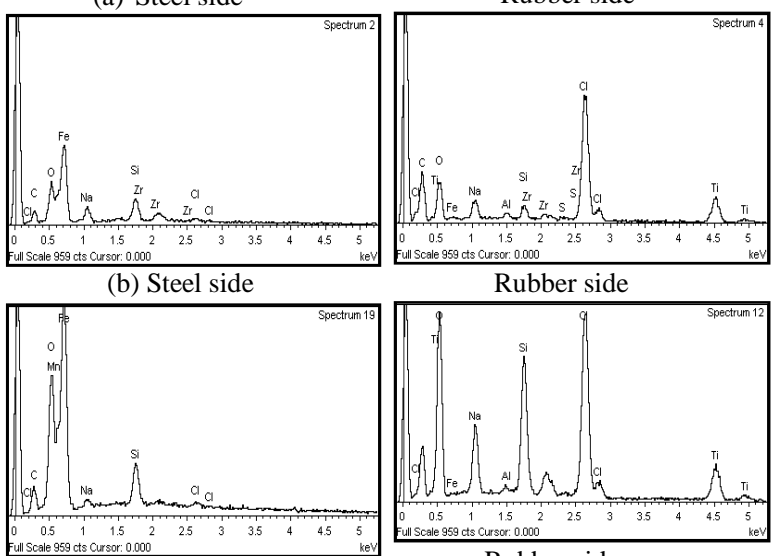

(c) Steel side

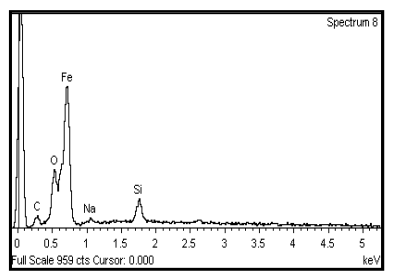

(d) Steel side

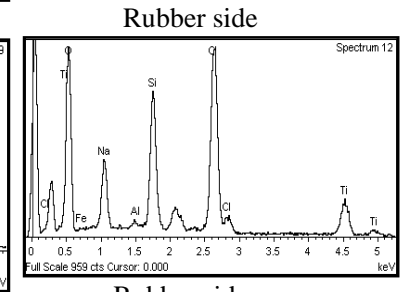

Rubber side

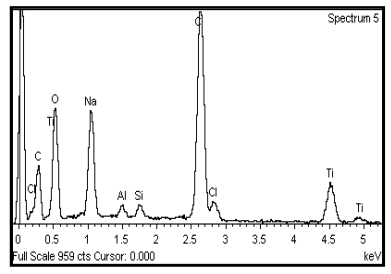

Rubber side

Fig. 2. EDS spectra on failed area after exposure in salt spray chamber at 35 oC. (a) rubber/220 sample (b) rubber/220/205 sample (c) 205 primer sample (d) 220/205 sample

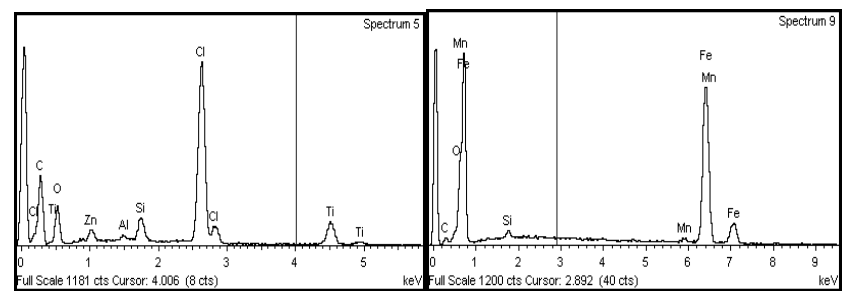

(a) Steel

(b) 205 primer

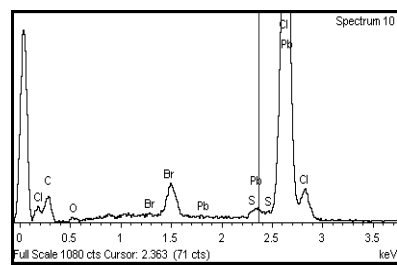

(c) 220 topcoats

Fig. 3. EDS spectra of reference samples (a) steel (b) 205 primer and (c) 220 topcoat.

\section{Adhesion Strength}

Rubber type failure was obtained when $90^{\circ}$ peel test was performed for the testpiece before exposure to the salt spray. However as expected over the exposure time, the primer/metal failure interface penetrates from the exposed edges towards the centre leaving the centre as a cohesive rubber failure, Fig. 6 . The peel strengths were reduced over the exposure time due to the reduction of the intact rubber on the steel demonstrated by Fig. 4. The results correlates well with [2] where the normalized peel strength over the rubber retention (Fig. 5) is slightly rose after the corrosive attack.

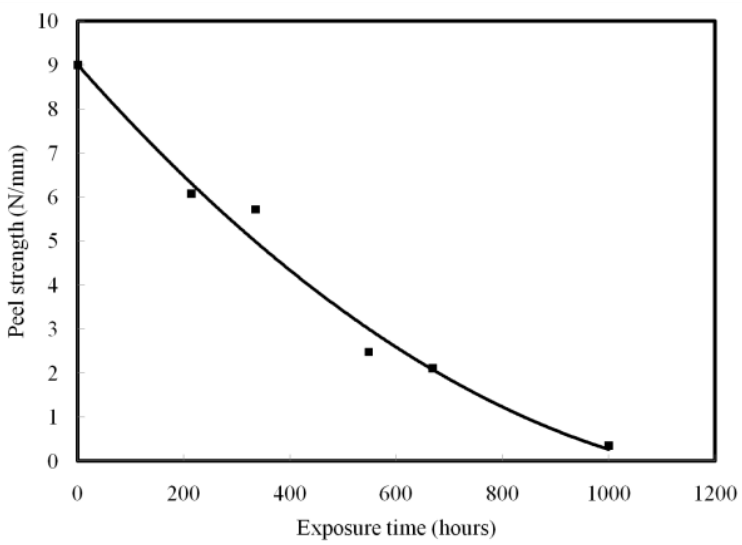

Fig. 4. Peel strength the bonded rubber by $205 / 220$ on polished mild steel over exposure time in salt spray cabinet at $35 \mathrm{oC}$

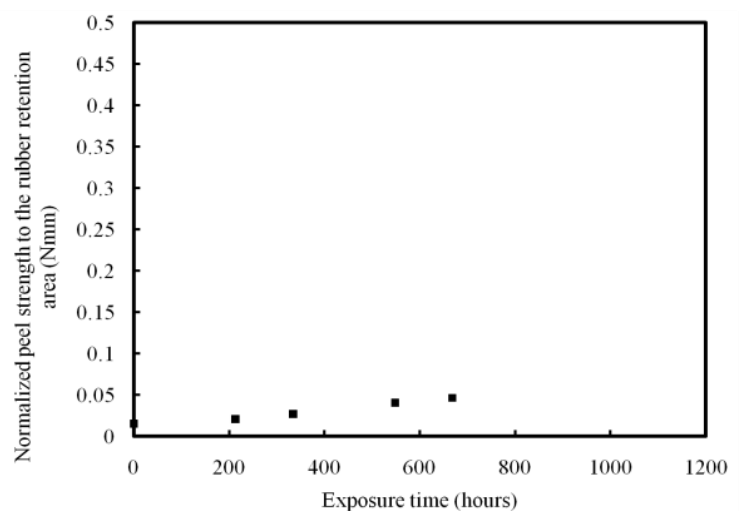

Fig. 5. Variation of normalized peel strength over rubber retention with exposure time in salt spray test chamber 


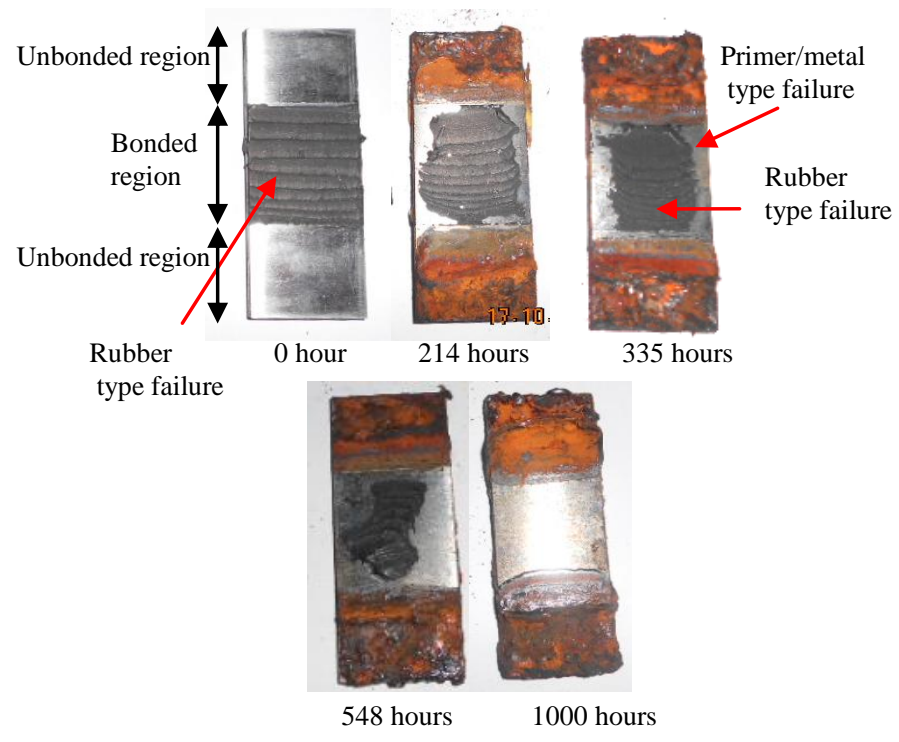

Fig. 6. Failure behaviour of peel test samples for rubber/220/205 on polished mild steel over exposure time in salt spray chamber at $35 \mathrm{oC}$

\section{ADHESION FAILURE MECHANISM}

The adhesives used to bond rubber to metal, the metal components corrode, and such corrosion process may compromise the performance of the adhesive joint, either at the bonded interface or adjacent to it. There are three distinct failure processes could occur on the adhesive joint durability; interfacial failure due to water hydrolysis of the adhesive from the substrate, the degradation of the adhesive itself in the environments, and the interfacial failure as a result of cathodic or anodic activity at the substrate, referred to as either cathodic delamination or anodic undermining [11]. He has reviewed that in some situation, there may be more than one mechanism in operation, and the one that proceeds fastest will invariably become the rate-controlling step. In this work, when exposed metal was heavily corroded after exposure in the salt spray cabinet and leads to the failure of the adhesive bond suggested that the bond failure of the rubber to metal may caused by a corrosion reaction. During corrosion, two reactions were involved which is oxidation and reduction process. The reaction take place involves the following steps [12]:

$$
\begin{aligned}
& \mathrm{Fe} \longrightarrow \mathrm{Fe}^{2+}+2 \mathrm{e} \\
& \mathrm{O}^{2}+2 \mathrm{H}_{2} \mathrm{O}+4 \mathrm{e} \stackrel{\mathrm{FH}^{-}}{\longrightarrow} 4 \mathrm{OH}^{2+}+1 / 2 \mathrm{O}_{2}+\mathrm{H}_{2} \mathrm{O}+6 \mathrm{OH}^{-} \longrightarrow \mathrm{FeO}^{-} \mathrm{Fe}_{2} \mathrm{O}_{3}+4 \mathrm{H}_{2} \mathrm{O} \\
& 3 \mathrm{Fe}^{2+} \mathrm{FeO}_{2} \mathrm{Fe}_{2} \mathrm{O}_{3}+3 \mathrm{H}_{2} \mathrm{O}+1 / 2 \mathrm{O}_{2} \longrightarrow 3 \mathrm{Fe}_{2} \mathrm{O}_{3} \cdot \mathrm{H}_{2} \mathrm{O}
\end{aligned}
$$

When the test pieces were exposed in the salt spray cabinet, the oxidation reaction take place at the exposed metal which in this case is at the edges and unbonded region for the peel test sample type caused the region to corrode and the electron produced are consumed at the cathodic site at the bond front where hydroxide ions are produced by the reduction of water and oxygen molecules. As reported by [11] and [13] the presence of $\mathrm{Na}+$ element on both failed sides from EDS analysis suggested that the cathodic reaction has occurs at the bond front and hence increases the alkalinity underneath the coating. Alkalinity produced leading to an increase in the $\mathrm{pH}$ at the adhesive-metal interface and hence attacks the interfacial bonding directly and contributes to the adhesion loss [14] and [15]. Bond detached on the test pieces observed here is may be due to the consequence of the generation of the alkalinity at the bond front. Therefore no sign of red rust formation underneath the coating after bond delamination which implies that the failure come first and then under film corrosion later. In this works EDS analysis discovered that the failure is interfacial between primer-metal interfaces implies that the primer itself prone to attack by this alkaline media. However more data is needed to prove the hypothesis and the work is currently under progress.

\section{CONCLUSIONS}

Rubber to metal bond is eventually failed when exposed in marine environment and the corrosion reactions take places on the exposed metal substrate. When visually observed on the failed region, the steel has a very clean shiny unrusted appearance suggested that the bond failure come first then corrosion later. The corroded area becomes the anodic region otherwise the reduction reaction takes place at the bond front which generates the alkaline media (hydroxide ions) and is believed attacking the bond. However more works are currently under progress to support this conclusion.

\section{ACKNOWLEDGMENT}

The author would like to thank the Universiti Teknologi MARA for permission to publish this paper and Malaysian Rubber Board for technical support of the works.

\section{REFERENCES}

[1] P. B. Lindley, "Ozone attack at a rubber metal bond," Journal of the IRI, vol. 5, no. 6, 1971.

[2] A. H. Muhr, M. Clotet, F. D. Persio, and S. Solanki, "Resistance of bonds in rubber components to corrosive environments," in Elastomers and components; service life prediction, V. A. Coveney, Cambridge: Woodhead Publishing in Materials, 2006.

[3] Y. Ishikawa and S. Kawarami, "Effects of salt corrosion on the adhesion of brass-plated steel cord to rubber," Rubber Chemistry and Technology, vol. 59, 1985.

[4] A. Stevenson, "On the durability of rubber/metal bonds in seawater," Int. Journal Adhesion and Adhesives, vol. 5, no. 2, pp. 81-91, 1985.

[5] A. Stevenson, "The effect of cathodic protection on rubber/metal bond durability in seawater," presented at the Discussion Forum and Exhibition on Offshore Engineering with Elastomers, Aberdeen, Scotland, 1985.

[6] A. Stevenson and B. Thomson, "Life prediction for rubber/metal bonds: the role of elevated temperature in accelerated testing," presented at the Rubber Bonding '98, 1998.

[7] F. J. Boerio and S. G. Hong, "Degradation of rubber-to-metal bonds during simulated cathodic delamination," Journal of Adhesion, vol. 30, pp. 119-134, 1989

[8] Physical testing of rubber, determination of rubber to metal bond strength, BS 903 part A21-1997.

[9] Standard practice for operating salt spray (fog) apparatus, ASTM B117-2007.

[10] Standard test methods for measuring adhesion by tape test, ASTM D3359-2009.

[11] J. F. Watts, "3.36 - Role of Corrosion in the Failure of Adhesive Joints" in Shreir's Corrosion, J. A. R. Editor-in-Chief: Tony (Ed Oxford: Elsevier.), 2010, pp. 2463-2481.

[12] D. A. Jones, Principles and prevention of corrosion, United States of America: Macmillan Publishing Company, 1992. 
[13] H. Leidheiser Jr, W. Wang, and L. Igetoft, "The mechanism for the cathodic delamination of organic coatings from a metal surface," Progress in Organic Coatings, vol. 11, pp. 19-40, 1983.

[14] H. Leidheiser Jr, "Mechanism of de-adhesion of organic coatings from metal surfaces" in Proc. Polymeric Materials for Corrosion Control $190^{\text {th }}$ Meeting of the American Chemical Society, Chicago, IL, USA, 1986, pp. 124-135.

[15] J. J. Ritter and J. Kruger, "A qualitative ellipsometric-electrochemical approach to the study of film growth under organic coatings," Surface Science, vol. 96, pp. 364-374, 1980.

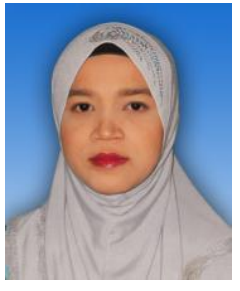

Ismaliza Ismail was born in Kelantan, Malaysian on 16th of December 1978. Ismaliza graduated with a BEng (hons) in Chemical Engineering from University of Manchester Institute Science \& Technology, Manchester, United Kingdom in 2001.

She is a researcher of engineering rubber products for Malaysian Rubber Board (MRB). Since joining MRB in 2005, she has carried out several researches on the use of rubber in engineering application such as rubber in offshore, railway system and, structure and automotive. She is also responsible to use CAE technologies as a part of the design method such as ABAQUS. Currently she is further her studies in Master of Science (MSc) in corrosion and adhesion science field mainly for rubber to metal bond at Universiti Teknologi MARA, Shah Alam, Selangor, Malaysia. 